\title{
Model studies of THz-range generation by down-conversion in GaSe and GaSeS crystals
}

\author{
D.M. Lubenko ${ }^{1,2}$, V.F. Losev ${ }^{1,2,3}$, Yu.M. Andreev ${ }^{2,4}$, G.V. Lanskii ${ }^{2,4}$ \\ ${ }^{1}$ High Current Electronics Institute SB RAS, 2/3, Akademicheskii Ave., 634055, Tomsk, Russia, \\ lideru@gmail.com; \\ ${ }^{2}$ National Research Tomsk State University, 36, Lenina Ave., 634050, Tomsk, Russia; \\ ${ }^{3}$ National Research Tomsk Polytechnic University, 30,LeninaAve., 634050, Tomsk, Russia; \\ ${ }^{4}$ Institute of Monitoring of Climatic and Ecological Systems SB RAS, 10/3,Akademicheskii \\ Ave.,634055, Tomsk, Russia;
}

\begin{abstract}
Model study of not phase matched and phase matched optical rectification or down-conversion of Ti:Sapphire laser pulses at $950 \mathrm{~nm}$ into $\mathrm{THz}$ and far-IRrange in pure and S-doped GaSe single crystals is carried out. First, the ordinary and extraordinary wave dispersions of the GaSe refractive indices were measured by terahertz time-domain spectroscopy (THz-TDS). Measured data were approximated in the form of Sellmeier dispersion equations for $0.62-2000 \mu \mathrm{m}$ range with using available shorter wave data.
\end{abstract}

Keywords:GaSe crystal, model study, nonlinear optics, $\mathrm{THz}$

\section{INTRODUCTION}

Over the past decades, frequency conversion through using phase matchable (anisotropic) nonlinear crystals has found more and more applications in producing THz coherent sources. The key to this technique lies in the nonlinear crystals, as they have to possess low optical loss, high damage threshold and large nonlinearity coefficient leading to high output power and hence can meet the increasing power demand in various applications. Besides, crystals should be hard for easy access and processing at arbitrary direction with fine finish. However, there is limited number of anisotropic inorganic nonlinear crystals suitable for $\mathrm{THz}$ applications that always possess much lower optical loss, higher damage threshold and larger hardness to that for organic crystals. Small optical loss and higher pump intensity is resulting in higher conversion efficiency. Larger hardness made easy access and processing at arbitrary direction.

Most suitable inorganic acentrosymmetric crystals for $\mathrm{THz}$ frequency converters are $\mathrm{ZnGeP}_{2}{ }^{1,2,3}, \varepsilon^{-\mathrm{GaSe}^{4,5}}$ (herein after $\mathrm{GaSe}$ ), $\mathrm{AgGaSe}_{2}{ }^{6}, \mathrm{AgGa}_{1-\mathrm{x}} \mathrm{In}_{\mathrm{x}} \mathrm{Se}_{2}{ }^{6}$ and $\mathrm{Tl}_{3} \mathrm{AsSe}_{3}{ }^{7}$ crystals. Among them, GaSe crystal is of extra interest due to extreme physical properties that allowed broadband highly efficiency parametric frequency conversion. For example, DFG within 2.7-38.4 \& 58.2-3540 $\mathrm{mm}^{8}$ and further up to $5640 \mu^{4}$ is realized ${ }^{6}$. In the total, frequency conversion is realized within $0.7895-5640 \mu \mathrm{m}^{4,8,9}$; output power THz pulse power reached is up to $2 \mathrm{~kW}^{10}$; up to $10-50 \mathrm{MW}$ is predicted. Interesting way for generation of $\mathrm{THz}$ emission, by realizing of parallel sum frequency generation of one non-selective $\mathrm{CO}$ laser, and difference frequency generation of sum frequencies and rest pump emission in a single GaSe sample at fixed angular position was recently proposed ${ }^{11}$.

Many of the unique physical properties of GaSe are associated with its layered structure. The basic four-fold layer consists of two monoatomic sheets of Ga sandwiched between two monoatomic sheets of Se. The strong covalent interaction within the atomic layers and week, Van-der-Waals type bonding between basic layers, renders GaSe as a highly anisotropic material. On the other hand, the layer structure results in extreme low hardness (almost zero by Mohs scale) and easy cleaving along planes parallel to the atomic layers, and finally in hampering of out-of-door large-area crystals applications.

Fortunately, an originale-polytype structure of GaSe is strengthening doping with different elements, as well other physical properties responsible for frequency conversion efficiency are modifying. It allowed easier processing at arbitrary directions and improves frequency conversion efficiency. Modified properties and improved efficiencies are

International Conference on Atomic and Molecular Pulsed Lasers XII, edited by Victor F. Tarasenko,

Andrey M. Kabanov, Proc. of SPIE Vol. 9810, 98101T · (c) 2015 SPIE

CCC code: $0277-786 \mathrm{X} / 15 / \$ 18 \cdot$ doi: $10.1117 / 12.2224939$

Proc. of SPIE Vol. $981098101 \mathrm{~T}-1$ 
reported for a number of doped crystals: light (GaSe:S) and heavely S-doped GaSe crystals that also referred to as solid solution crystals GaSe:GaS (GaSe ${ }_{1-x} S_{x}$, where $x$ is mixing ratio) ${ }^{12,13,14,15,16}$, GaSe:In and $\mathrm{Ga}_{1-\mathrm{x}} \mathrm{In}_{\mathrm{x}} \mathrm{Se}^{17,18,19,20,21}$, GaSe:Te and $\mathrm{GaSe}_{1-\mathrm{x}} \mathrm{Te}_{\mathrm{x}}{ }^{19,22,23}$, doped GaSe:Er ${ }^{24,25,26}, \mathrm{GaSe}_{\mathrm{Al}} \mathrm{Al}^{27,28,29}, \mathrm{GaSe}: \mathrm{Ag}^{30}$, and GaSe:InSe or $\mathrm{Ga}_{1-\mathrm{x}} \mathrm{In}_{\mathrm{x}} \mathrm{Se}_{1-\mathrm{y}} \mathrm{S}_{\mathrm{y}}{ }^{31}$ crystals. Increased frequency conversion efficiency is recorded for frequency conversion into both mid-IR ${ }^{13,17,18,20}$ and $\mathrm{THz}^{32,33,34,35}$ range. Recently, summarized data were presented in few papers ${ }^{36-40}$, which consider some other double element doped GaSe crystals. Strengthened structuregives opportunity of the application in out-of-door applied systems $^{41}$.

Due to a set of modified parameters: increased damage threshold, decreased phase matching angle, lower absorption and refraction, short-wavelength shifted transparency and phase matching ranges etc. the highest frequency conversion efficiency was recorded for solid solution $\mathrm{GaSe}_{1-\mathrm{x}} \mathrm{S}_{\mathrm{x}}$ crystals ${ }^{13,33,34}$. In particular, for $\mathrm{Er}^{3+}$ :YAG laser SHG conversion efficiency in optimally composition $\mathrm{GaSe}_{1-\mathrm{x}} \mathrm{S}_{\mathrm{x}}$ crystal was of 2.4 times higher to that for pure GaSe crystal, as well as for $\mathrm{THz}$ generation by Ti:Sapphire laser frequency down-conversion. In contradiction, negative effects of S-doping on the optical damage threshold and on frequency conversion efficiency were also reported ${ }^{16,42}$ that reflect doping-induced degradation in optical quality.

In fact, differences in the state-of-the-art of growth technology, limited distribution of doped GaSe crystals and still problematic cut and high optical quality polishing of pure and doped GaSe crystals are reasons of paucity and highly scattered data on optical properties of pure and doped GaSe crystals in THz range. Until recently Due to limited distribution and hard processing absorption spectra for e-wave in $\mathrm{GaSe}_{1-\mathrm{x}} \mathrm{S}_{\mathrm{x}}$ crystals (i.e. absorption anisotropy properties) in the $\mathrm{THz}$ range have only been studied for two solid solution compositions: $\mathrm{GaSe}_{0.74} \mathrm{~S}_{0.26}{ }^{15}$ and $\mathrm{GaSe}_{0.71} \mathrm{~S}_{0.29}{ }^{16}$. From data in these studies and measurements at fixed frequencies ${ }^{4,34}$ it was established that the absorption coefficient $\alpha_{0}$ exceeds $\alpha_{\mathrm{e}}$ at THz frequencies as it does in the pure GaSe crystal. This difference in absorption loss leads to a higher efficiency of $\mathrm{THz}$ e-wave generation ${ }^{8,34}$. It was also predicted and confirmed experimentally that the uncommon ee-e type of interaction can be realized in pure and S-doped GaSe crystals ${ }^{15,16}$.

Successful design of $\mathrm{THz}$ sources calls for adequate data on PM possibilities and potential efficiencies for all possible three frequency interactions. In turn, it needs in correct data on dispersion properties and absorption spectra over the entire transparency range for pure and S-doped GaSe and solid solution $\mathrm{GaSe}_{1-\mathrm{x}} \mathrm{S}_{\mathrm{x}}$ crystals as a function of the mixing ratio. Correct data are a crucial factor in the selection of the most efficient type of three frequency interactions and in maximizing the frequency conversion efficiency. Original processing technology allowed fabrication of a range of high optical quality S-doped crystals at $\theta=90^{\circ}$. Recently, by using these and cleaved samples of the same composition, refractive indices for ordinary (o) and extraordinary (e) waves were successfully measured ${ }^{43}$. However, analyses of phase matching were not carried out.

In the present work, we report model study of phase matching for different typesof three frequency interactions in GaSe and $\mathrm{GaSe}_{1-\mathrm{x}} \mathrm{S}_{\mathrm{x}}$ crystals by using designed dispersion equations.Two Ti:Sapphire lasers that are available in our lab (operating, respectively, at $950 \mathrm{~nm}$ and $980-1080 \mathrm{~nm}$ ) are considered as pump sources.

\section{CRYSTAL GROWTH AND CHARACTERIZATION}

A modified synthesis of polycrystalline material and the vertical Bridgman single crystal growth method were employed to grow single crystals of solid solution $\mathrm{GaSe}_{1-\mathrm{x}} \mathrm{S}_{\mathrm{x}}$. The starting materials for the synthesis were Ga 99.9997, Se 99,99 and $\mathrm{S}$ 99.95. The stoichiometric charge of $\mathrm{Ga}$ and $\mathrm{Se}$, and the nominal $0,1.1,2.5,5,7$ mass.\% $\mathrm{S}(\mathrm{x}=0,0.05,0.11,0.22$, $0.29,0.44)$ was weighed out. Synthesis ampoules were loaded up to $65 \%$ in volume to minimize the quantity of residual gases and cosequent interaction so as to improve optical quality. Other details on the synthesis process are reported elsewhere ${ }^{44}$. After several hours of melt homogenization during the synthesis process, the temperature was slowly decreased to $40 \mathrm{~K}$ below the melting point of $1238 \mathrm{~K}$ of the compound at the rate of $\sim 10 \mathrm{~K} / \mathrm{h}$. For the growth process, the polycrystalline material was loaded into a single wall cylindrical ampoule. The internal surface had a layer of pyrolytic carbon which protected the melt from reaction with the ampoule wall material and impurities. The unseeded crystal growth was performed by the vertical Bridgman method with heat field symmetry change and the symmetry center moving all over the oven space that is described elsewhere ${ }^{45,46}$. The sealed growth ampoule was loaded into a furnace having a temperature gradient of $\sim 15 \mathrm{~K} / \mathrm{cm}$ at the estimated level of crystallization front. After homogenization of the melt at the temperature $30 \mathrm{~K}$ above the melting point, the ampoule was mechanically lowered at the speed of $10 \mathrm{~mm} /$ day. No eutectic was found by visual examination. The grown boule allows easy sample cleaving with high optical quality surfaces up until the end section.Photos of doped GaSe crystals are shown in Fig. 1. 


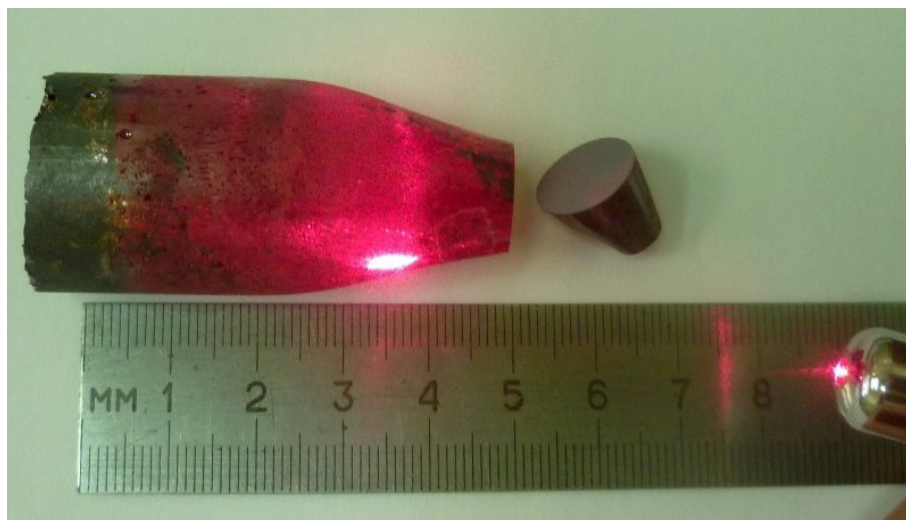

a

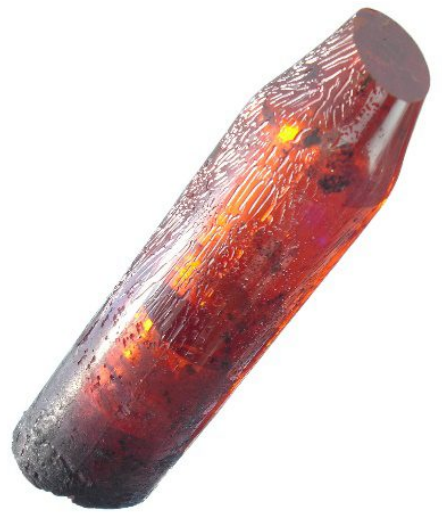

$\mathrm{b}$

Figure 1.External view on as-grown high quality GaSe:Scrystals: (a) 1 mass $\%$ and (b) 11 mass $\%$ S-doped.

Two types of $\mathrm{GaSe}_{1-\mathrm{x}} \mathrm{S}_{\mathrm{x}}$ samples were fabricated for the present study. The first type was cleaved from as-grown boules, i.e. it had faces orthogonal to the c-axis, so that a beam traversing the sample travelled parallel to the c-axis. The high optical quality of these samples can be estimated by the naked eye, evident in their transparency and homogenity. The second type was mechanically cut and polished. These samples were made by first immersing a section of the $\mathrm{GaSe}_{1-\mathrm{x}} \mathrm{S}_{\mathrm{x}}$ boule in monomer (polymetil crylate) mixed with a thermoinitiator and placed in an oven for polymerization for 2 hours. The produced samples of both types were free from precipitates, voids or micro bubbles, or other visual defects.

Optical properties in mid-IR range were studied by using homemade spectrophotometers but THz-TDS (time-domain spectroscopy) measurements of o- $\left(\alpha_{0}\right)$ and e-wave $\left(\alpha_{e}\right)$ absorption coefficient spectra and absorption anisotropy in the 0.3-4.0 THz range for solid solution crystals $\mathrm{GaSe}_{1-\mathrm{x}} \mathrm{S}_{\mathrm{x}}$ as it is described in details elsewhere ${ }^{39,40}$ and commerce Z-3 (Zomega, USA) spectrometer. It was found that grown GaSe crystals possesses from 2 to 3 times lower absorption coefficient that crystals grown by common syntheses and single crystal growth technology. In line, optimally 2-3 mass $\%$ S-doped GaSe crystals also demonstrated 2-3 times lower absorption coefficient to that for pure GaSe crystals grown by modified technology. So such, it seems us that measurement results are quite adequate.

\section{MODEL STUDY}

Dispersion properties for $\mathrm{GaS}$ and $\mathrm{GaSe}$ were measured in $\mathrm{THz}$ range and approximated in the form of dispersion equations all over the entire transparency range. Available data for from visible to through mid-IR were also used in the approximation $^{43}$.

Phase matching angles for difference frequency generation (DFG) were calculated by using well known relations:

$$
\frac{1}{\lambda_{\text {pump }}}=\frac{1}{\lambda_{\text {signal }}}-\frac{1}{\lambda_{\text {idle }}}
$$

considering phase matching condition as $\mathrm{k}_{\mathrm{s}}-k_{i}-k_{p} \leq 10^{-4}$. In relation (1)

$$
k_{0}=\frac{n_{o}}{\lambda},
$$




$$
k=\frac{\frac{n_{0} n_{e}}{\sqrt{n_{o}^{2} \sin ^{2} \theta+n_{e}^{2} \cos ^{2} \theta}}}{\lambda} .
$$

Dispersion equations for the entire transparency range of $\mathrm{GaSe}^{43}$ :

$$
\begin{aligned}
& n_{o}^{2}=10.6409+\frac{0.3788}{\lambda^{2}-0.1232}+\frac{6963.32}{\lambda^{2}-2198.85}+\frac{0.017 \lambda^{2}}{\lambda^{2}-262177.5577}, \\
& n_{e}^{2}=5.76+\frac{3879}{\lambda^{2}}-\frac{0.2288}{\lambda^{4}}+\frac{0.1223 \lambda^{2}}{\lambda^{6}}+\frac{0.4206 \lambda^{2}}{\lambda^{2}-1780.3} .
\end{aligned}
$$

Dispersion equations for the entire transparency range of $\mathrm{GaS}^{47}$ :

$$
\begin{gathered}
n_{o}^{2}=-\frac{0.01129}{\lambda^{6}}+\frac{0.03648}{\lambda^{4}}+\frac{0.51402}{\lambda^{2}}+6.59624+\frac{2.71047 \lambda^{2}}{\lambda^{2}-1025.42116} \\
n_{e}^{2}=\frac{0.0113}{\lambda^{6}}+\frac{0.10569}{\lambda^{4}}-\frac{0.44573}{\lambda^{2}}+4.92144+\frac{0.315 \lambda^{2}}{\lambda^{2}-720.12225} .
\end{gathered}
$$

Phase matching estimation for solid solution crystals $\mathrm{GaSe}_{1-\mathrm{x}} \mathrm{S}_{\mathrm{x}}$ can be carried out by using relationship proposed in ${ }^{48}$ that is, in particular, adapted for solid solution $\mathrm{GaSe}: \mathrm{GaS} \mathrm{in}^{49}$ as follows:

$$
n_{o, e}^{2}\left(\operatorname{GaSe}_{1-x} S_{x}\right)=(1-x) n_{o, e}^{2}(G a S e)+x n_{o, e}^{2}(G a S)
$$




\section{RESULTS AND DISCUSSION}

Calculated dispersions and birefringence for pure and S-doped GaSe crystals are presented in the Fig. 2-5.

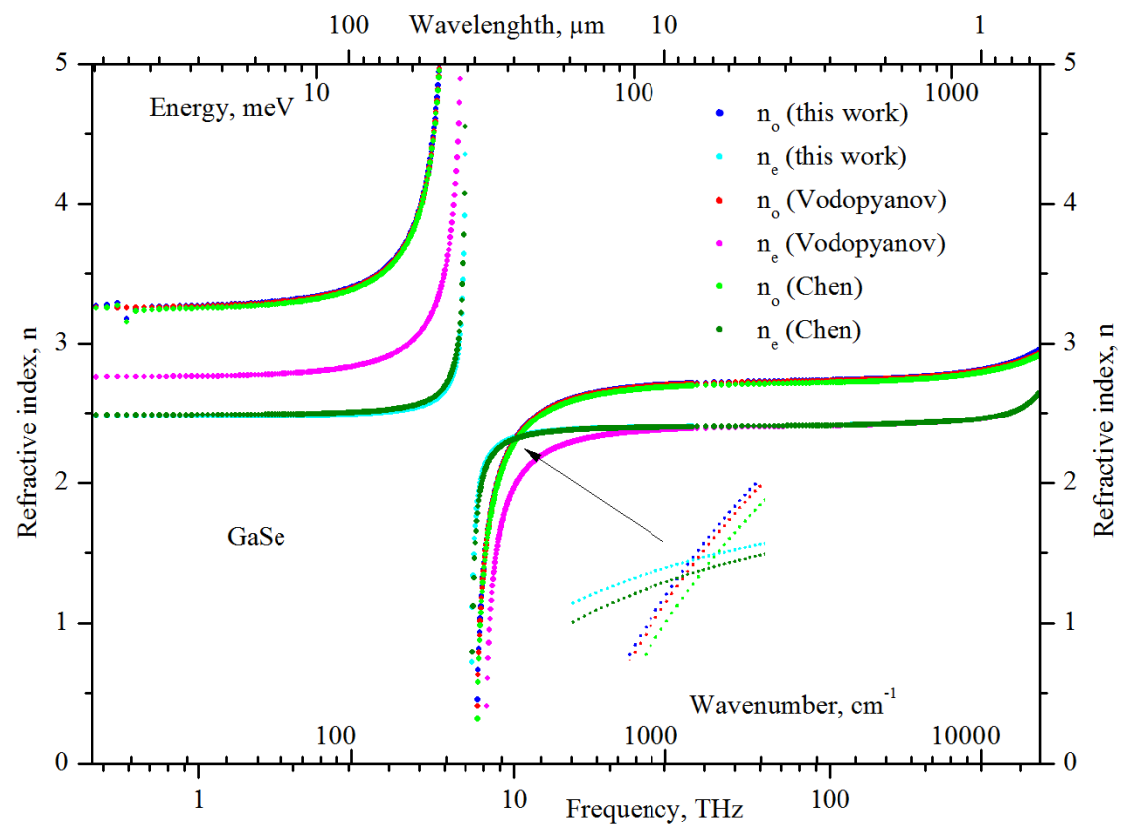

Figure 2. Comparison calculated refraction indices for GaSe crystal.

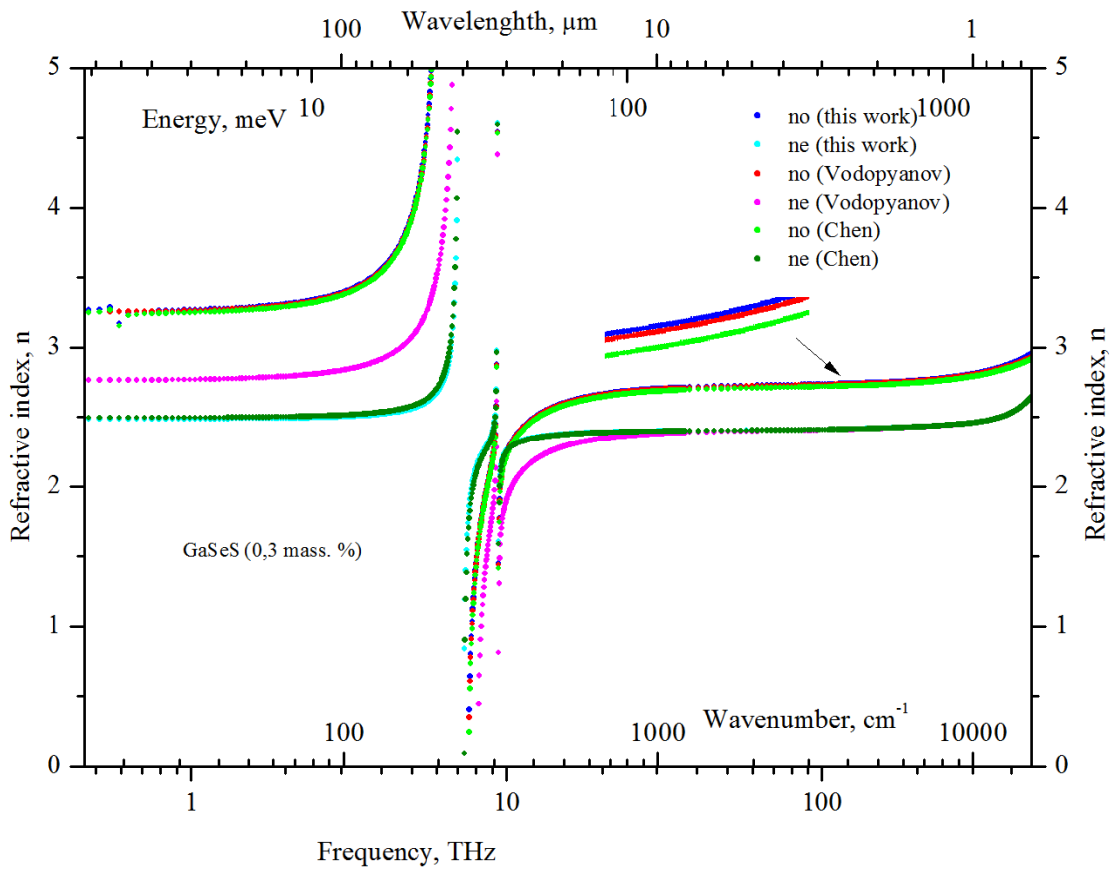

Figure 3. Comparison calculated refraction indices for $\operatorname{GaSeS}(0.3$ mass $/ \%)$ crystal 


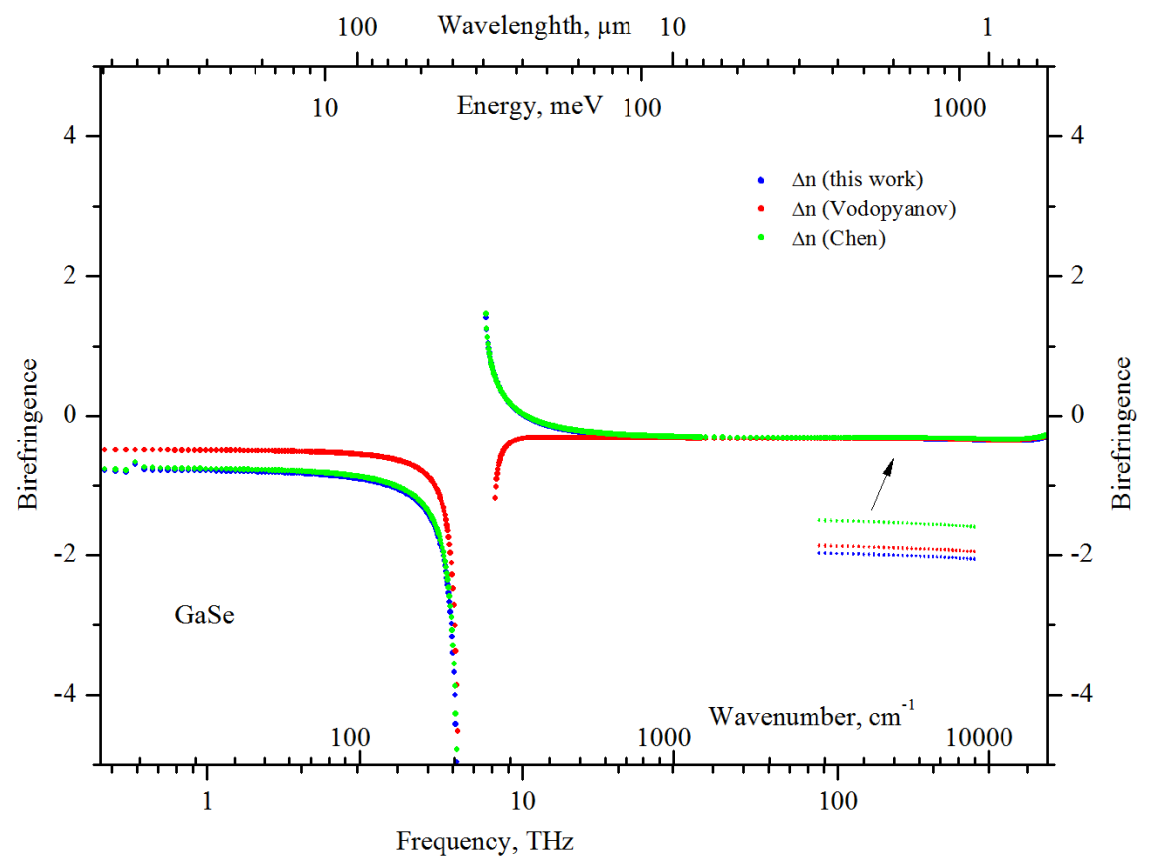

Figure 4. Comparison calculated birefringence for GaSe crystal

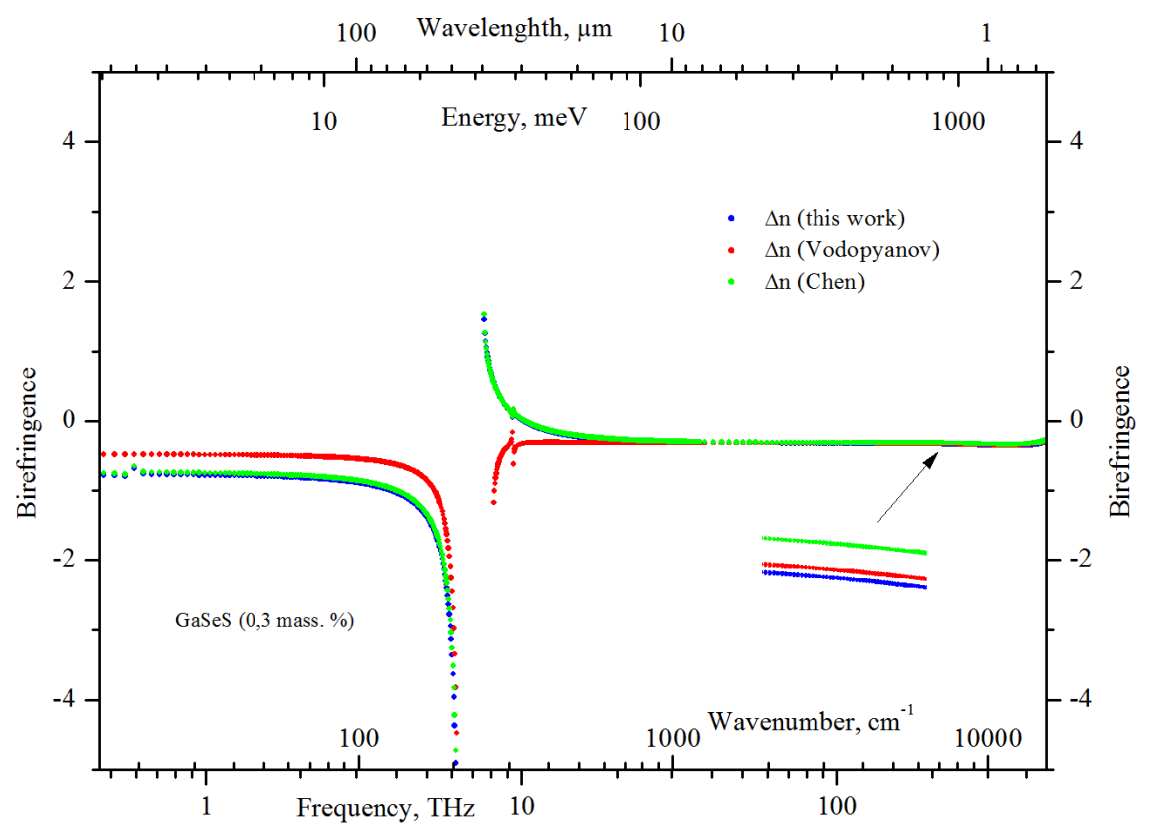

Figure 5. Comparison calculated birefringence for GaSeS (0.3 mass.\%) crystal 
In Fig. 2-5 it is seen that $n_{e}$ dispersions in the THz range recorded in this study are huge, almost for 2 times, different as estimated from widely used dispersion equations from Vodopyanov et all. On the one hand, recorded data are close to that determined by Chen and earlier measured data ${ }^{50}$.

DFG PM estimated by using different dispersion equations ${ }^{51,52}$ for interactions resulting in e-wave $\mathrm{THz}$ generation are plotted for comparison in Fig. 6,7.

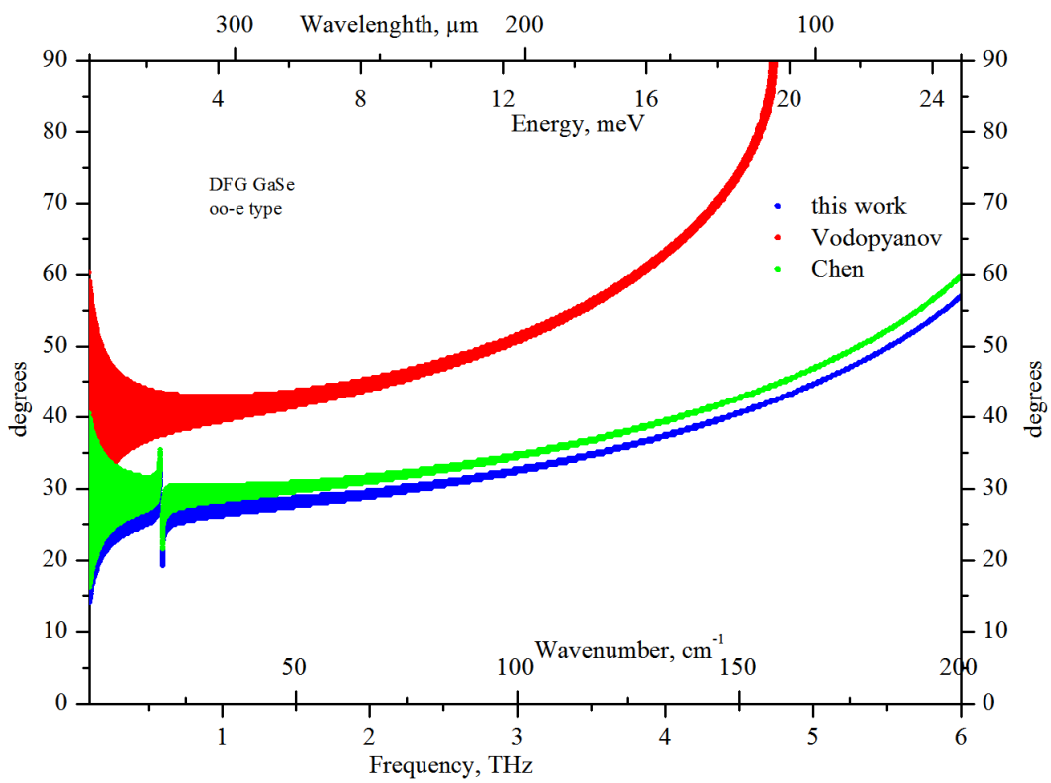

Figure 6. Comparison of calculated PM angles for GaSe crystal foroo-e interaction type

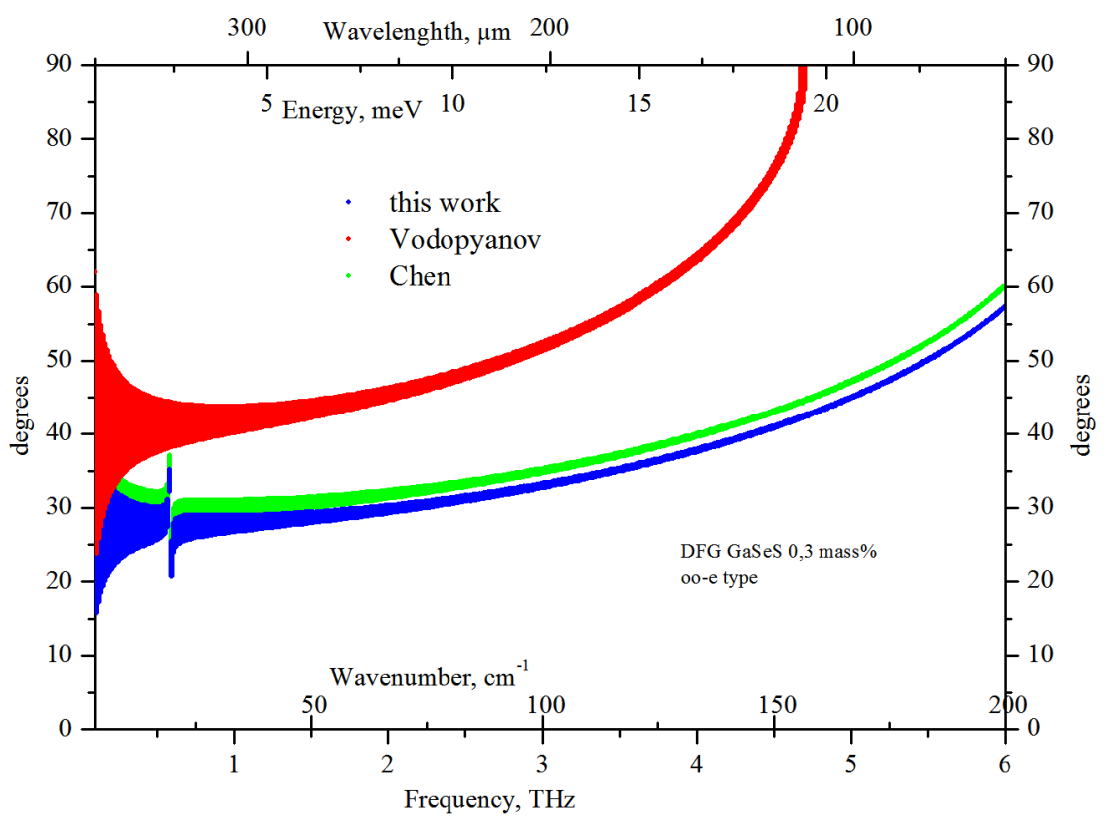

Figure 7. Comparison of calculated PM angles for GaSeS ( 0.3 mass $/ \%)$ crystal for oo-e interaction type.

In Fig.6-7 it is seen that, as it should be bearing in mind differences in $n_{e}$ dispersions in Fig.2-5, PM conditions for downconversion of 930 and $970 \mathrm{~nm}$ Ti:Sapphire lasers estimated by using dispersion equations by Vodopyanov et all. differ significantlyto that estimated with new proposed ${ }^{47}$ and Chen's et all. ${ }^{51}$ equations. On the other hand, it is in contradiction 
with the fact of wide using of Vodopyanov's dispersion equations and well matching of experimental and estimated PM angles. It can be explained by differences in the magnitudes of PM angles for considered down-conversion processes. Common down-conversion process in published papers arerelated to down-conversion of $1.064 \mu \mathrm{m} \mathrm{Nd:YAG} \mathrm{laser} \mathrm{and}$ OPO operating at close wavelengths. It occurs at small internal PM angles anything like 2-4 degrees. In this case, $\mathrm{n}_{\mathrm{e}}$ magnitudes are close to $n_{o}$ magnitudes that are identical for all dispersion equations presented in Fig. 2-5. For down conversion of Ti:Sapphire lasers PM angles are large and difference in the $\mathrm{n}_{\mathrm{e}}$ dispersion became important. It resulted in significant differences of PM angles.

This result is very important for our prospective study on down-conversion of available $950 \mathrm{~nm}$ as and tunable $780-1080$ nm Ti:Sapphire lasers.

\section{CONCLUSION}

Improved quality crystals were grown by modified technology and used in these measurements. Dispersion properties of $\mathrm{o}$ - and e-wave refractive indices and absorption coefficients for GaSe and $\mathrm{GaSe}_{1-\mathrm{x}} \mathrm{S}_{\mathrm{x}}$ crystals were preliminary measured by THz-TDS, approximated in the equation form and then used in the study. Model study of THz generation in pure and solid solution $\mathrm{GaSe}_{1-\mathrm{x}} \mathrm{S}_{\mathrm{x}}$ crystals by Ti:Sapphire laser is carried out.

Acknowledgment: The authors are grateful for partial financial support to RFBR Project No. 15-19-10021.

\section{REFERENCES}

[1] Boyd G.D., Bridges T.J., Patel C.K.N., Buehler E., "Phase-matched submillimeter wave generation by differencefrequency mixing in $\mathrm{ZnGeP}_{2}$," Appl. Phys. Lett. 21 (11), 553-555 (1972).

[2] Andreev Yu.M., Apollonov V.V., ShakirYu.A., Verozubova G.A., Gribenyukov A.I., "Submillimeter-wave generation with $\mathrm{ZnGeP}_{2}$ crystals," J. Korean Phys. Soc. 33 (3), 320-325 (1998).

[3] Ding Y.J., "High-Power Tunable Terahertz Sources Based on Parametric Processes and Applications," IEEE J. Select. Topics QE, V. 13, N.3 (2007).

[4] Ding Y. J., Shi W., "Widely tunable monochromatic THz sources based on phase-matched difference-frequency generation in nonlinear-optical crystals: A novel approach," Las. Phys. 16 (4), 562-570 (2006).

[5] Yun-Shik Lee, [Principle of terahertz science and technology], Springer, New York, 340 (2008).

[6] Apollonov V.V., Lebedev S.P., Komandin G.A., ShakirYu.A., Badikov V.V., Andreev Yu.M., Gribenyukov A.I., "High power $\mathrm{CO}_{2}$-laser radiation conversion with $\mathrm{AgGaSe}_{2}$ and $\mathrm{AgGa}_{1-\mathrm{x}} \mathrm{In}_{\mathrm{x}} \mathrm{Se}_{2}$ crystals," Las. Phys. 9 (6), 12361239 (1999).

[7] Singh N.B., Norris T.B., Buma T., Singh R.N., Gottlieb M., Suhre D., Hawkins J.J., "Properties of nonlinear optical crystals in the terahertz wavelength region," Opt. Engin. 45 (9), 094002 (2006).

[8] Wei Shi,Yujie J. Ding "A monochromatic and high-power terahertz source tunable in the ranges of 2.7-38.4 and 58.2-3540 $\mu \mathrm{m}$ for variety of potential applications," Appl. Phys. Lett. 84 (10), 1635-1637 (2004).

[9] Kador L., Haarer D., Allakhverdiev K.R., SalaevE.Yu., "Phase-matched second-harmonic generation at $789.5 \mathrm{~nm}$ in a GaSe crystal," Appl. Phys. Lett. 69 (6), 731-733 (1996).

[10] Sergei Ya. Tochitsky, Chieh Sung, Sarah E. Trubnick, Chan Joshi, Konstantin L. Vodopyanov, "High-power tunable, $0.5-3 \mathrm{THz}$ radiation source based on nonlinear difference frequency mixing of $\mathrm{CO}_{2}$ laser lines," J. Opt. Soc. Am. B. V. 24. N. 9, 2509-2516 (2007).

[11] Andreev Yu.M., Budilova O.V., Ionin A.A., Kinyaevskiy I.O., KlimachevYu.M., Kotkov A.A., KozlovA.Yu., "Frequency conversion of mode-locked and Q-switched CO laser radiation with efficiency up to 37\%," Optics Letters, V.40, Issue 13, 2997-3000 (2015).

[12] Allahverdiev K.R., Guliev R.I., SalaevE.Yu., Smirnov V.V., "Investigation of linear and nonlinear optical properties of $\mathrm{GaS}_{\mathrm{x}} \mathrm{Se}_{1-\mathrm{x}}$ crystals," Quantum Electronics 12 (7), 947-948 (1982).

[13] Zhang H.-Z., Kang Z.-H., Jiang Yu., Gao J.-Yu., Wu F.-G., Feng Z.-S., Andreev Yu.M., Lanskii G.V., Morozov A.N., Sachkova E.I., SarkisovS.Yu., "SHG phase matching in $\mathrm{GaSe}$ and mixed $\mathrm{GaSe}_{1-\mathrm{x}} \mathrm{S}_{\mathrm{x}}, \mathrm{x} \leq 0.412$, crystals at room temperature," Opt. Exp. 16 (13), 9951-9957 (2008).

[14] Luo Z.-W., Gu X.-A., Zhu W.-C., Tang W.-C., Andreev Yu., Lanskii G., Morozov A., Zuev V., "Optical properties of GaSe:S crystals in terahertz frequency range," Opt. Precision Eng. 19 (2), 354-359 (2011).

[15] Zhang L.-M., Guo J., Li D.-J., Xie J.-J., Andreev Yu.M., Gorobets V.A., Zuev V.V., Kokh K.A., Lanskii G.V., 
Petukhov V.O., Svetlichnyi V.A., Shaiduko A.V., "Dispersion properties of $\mathrm{GaSe}_{1-\mathrm{x}} \mathrm{S}_{\mathrm{x}}$ in the terahertz range," J. Appl. Spectr. 77 (6), 850-856 (2011).

[16] SarkisovS.Yu., Nazarov M.M., Shkurinov A.P., Tolbanov O.P., "GaSe $e_{1-x} S_{x}$ and $\mathrm{GaSe}_{1-\mathrm{x}} \mathrm{Te}_{\mathrm{x}}$ solid solutions for terahertz generation and detection," Proc. of the 34th Int. Conf. on Infrared, Millimeter and Terahertz wave (IRMMW-THz-2009). 21-25 September, 2009. Busan, Korea, (2009).

[17] Suhre D. R., Singh N. B., Balakrishna V., Fernelius N. C., Hopkins F. K., "Improved crystal quality and harmonic generation in GaSe doped with indium," Opt. Lett. 22 (11), 775-777 (1997).

[18] Singh N.B., Suhre D.R., Rosch W., Meyer R., Marable M., Fernelius N.C., Hopkins F.K., Zelmon D.E., Narayanan R., "Modified GaSe crystals for mid-IR applications," J. Cryst. Growth 198, 588-592 (1999).

[19] Mandal K.C., Kang S.H., Choi M., Chen J., Zhang X.-C., Schleicher J.M., Schmuttenmaer C.A., Fernelius N.C., "III-VI chalcogenide semiconductor crystals for broadband tunable THz sources and sensors," IEEE J. Select. Topics Quant. Electron. 14 (2), 284-288 (2008).

[20] Feng Z.-S., Kang Z.-H., Wu F.-G., Gao J.-Yu., Jiang Yu., Zhang H.-Z., Andreev Yu.M., Lanskii G.V., Atuchin V.V., Gavrilova T.A., "SHG in doped GaSe:In crystals," Opt. Exp. 16 (13), 9978-9985 (2008).

[21] RakZs., Mahanti S.D., Mandal K.C., Fernelius N.C., "Doping dependence of electronic and mechanical properties of $\mathrm{GaSe}_{1-\mathrm{x}} \mathrm{Te}_{\mathrm{x}}$ and $\mathrm{Ga}_{1-\mathrm{x}} \mathrm{In}_{\mathrm{x}} \mathrm{Se}$ from first principles," Phys. Rev. B 82, 155203 (2010).

[22] Andreev Yu.M., Lanskii G.V., Orlov S.N., PolivanovYu.N., "Physical properties, phase matching and frequency conversion in $\mathrm{GaSe}_{1-\mathrm{x}} \mathrm{S}_{\mathrm{x}}, \mathrm{Ga}_{1-\mathrm{x}} \mathrm{In}_{\mathrm{x}} \mathrm{Se}$ and $\mathrm{GaSe}_{1-\mathrm{x}} \mathrm{Te}_{\mathrm{x}}, "$ XVII Int. Conf. On Advanced Laser Technol., 26 Sep. - 1 Oct. 2009, Kosaeli, Turkey, 55 (2009).

[23] Evtodiev I., Leontie L., Caraman M., Stamate M., Arama E., "Optical properties of p-GaSe single crystals doped with Te," J. Appl. Phys. 105, 023524 (2009).

[24] Chen Ch.-W., Hsu Yu-K., Huang J.Y., Chang Ch.-Sh., Zhang Ji.-Yu., Pan Ci-L., "Generation properties of coherent infrared radiation in the optical absorption region of GaSe crystal" Opt. Exp. 14 (22), 10636-10644 (2006).

[25] Yu-Kuei Hsu, Ching-Wei Chen, Jung Y. Huang, Ci-Ling Pan, Jing-Yuan Zhang, Chen-Shiung Chang, "Erbium doped GaSe crystal for mid-IR applications," 14 (12), 5484-5491 (2006).

[26] Feng Z.-S., Guo J., Xie J.-J., Zhang L.-M., Gao J.-Y., AndreevYu.M., Izaak T.I., Kokh K.A., Lanskii G.V., Shaiduko A.V., Shabalina A.V., Svetlichnyi V.A.,"GaSe:Er crystals for SHG in the infrared spectral range," Opt. Commun., V.318, 205-211 (2014).

[27] Zhang Y.-F., Wang R., Kang Z.-H., Qu L.-L., Jiang Y., Gao J.-Y., Andreev Yu.M., Lanskii G.V., Kokh K.A.,, Morozov A.N, Shaiduko A.V., Zuev V.V., "AgGaS $2_{2}$ and Al-doped GaSe crystals for IR applications," Opt. Commun. 284, 1677-1681 (2011).

[28] Guo J., Xie J.-J., Zhang L.-M., Li D.-J., Yang G.-L., Andreev Yu. M., Kokh K. A., Lanskii G. V., Shabalina A. V., Shaiduko A. V., Svetlichnyi V. A., "Characterization of Bridgman grown GaSe:Al crystals," CrystEngComm V. 15., 6323-6328 (2013).

[29] Guo J., Li D. J., Xie J. J., Zhang L. M., Kokh K.A., AndreevYu.M., Izaak T.I., Lanskii G.V., Shaiduko A.V., Svetlichnyi V.A.,"Characterization of optical quality of GaSe:Al crystals by exciton absorption peak parameters,"J. of Material Science: Materials in Electronics, V.25, Issue 4, 1757-1760 (2014).

[30] Xie J.-J., Guo J., Zhang L.-M., Li D.-J., Yang G.-L., Chen F., Jiang K., Evdokimov M.E., Nazarov M.M., Andreev Yu.M., Lanskii G.V., Kokh K.A., Kokh A.E., Svetlichnyi V.A., "Optical properties of non-linear crystal grown from the melt GaSe-AgGaSe," Opt. Commun. V. 287, 145-149 (2013).

[31] Feng Z.-S., Li S.M., Izaak T.I., Kokh K.A., Losev V.F., Lubenko D.M., Svetlichnyi V.A., Soldatov A.N., Shaiduko A.V.,"Optical properties of nonlinear solid solution crystals GaSe:InS," Russian Physics Journal, V.56, No.10/2, 58 (2013).

[32] Ku S.-A., Chu W.-C., Luo C.-W., Andreev Y.M., Lanskii G., Shaiduko A., Izaak T., Svetlichnyi V., Wu K.H., Kobayashi T., "Optimal Te-doping in GaSe for non-linear applications," Opt. Exp. 20 (5), 5029-5037 (2012).

[33] XieJi-Jiang, GuoJin, Zhang Lai-Ming, Chen Fei, Jiang Ke, Andreev Yu.M., Atuchin V.V., Gorobets V.A., Lanskii G.V., Svetlichnyi V.A., Shaiduko A.V., "Frequency conversion of nanosecond $\mathrm{CO}_{2}$-laser into $\mathrm{THz}$ range in doped GaSe crystals," Basic Problems Mat. Sci. 9 (4), 486-494 (2012).

[34] Jingguo Huang, Zhiming Huang, Jingchao Tong, Cheng Ouyang, Junhao Chu, Yury Andreev, Konstantin Kokh, GrigoryLanskii, Anna Shaiduko, "Intensive terahertz emission from $\mathrm{GaSe}_{0.91} \mathrm{~S}_{0.09}$ under collinear difference frequency generation," Appl. Phys. Lett. 103, 81104 (2013).

[35] Lubenko D.M., Losev V.F., Andreev Yu.M., Lanskii G.V., Svetlichnyi V.A.,"Generating femtosecond pulses in the mid-IR and THz ranges in GaSe1-xTex crystals," Bulletin of the Russian Academy of Sciences: Physics, V.79, No. 2, 238-241 (2015). 
[36] Guo J., Li D.-J., Xie J.-J., Zhang L.-M., Feng Z.-S., Andreev Yu.M., Kokh K.A., Lanskii G.V., Potekaev A.I., Shaiduko A.V., Svetlichnyi V.A., "Limit pump intensity for sulfur-doped gallium selenide crystals," Laser Phys. Lett., V.11, No.5, 055401 (2014).

[37] Feng Z.-S., Kang Z.-H.,Li X.-M.,GaoJ.-Y.,Andreev Yu. M.,Atuchin V.V.,Kokh K. A.,Lanskii G. V., Potekaev A.I., Shaiduko A.V., Svetlichnyi V.A., "Impact of fs and ns pulses on solid solution crystals $\mathrm{Ga}_{1-\mathrm{x}} \mathrm{In}_{\mathrm{x}} \mathrm{Se}$ and $\mathrm{GaSe}_{1-\mathrm{x}} \mathrm{S}_{\mathrm{x}}$," AIP Advances 4(3), 037104 (2014).

[38] Kokh K.A., Molloy J.F., Naftaly M., Andreev YuM., Svetlichnyi V.A., Lanskii G.V., Lapin I.N., Izaak T.I., Kokh A.E.,"Growth and optical properties of solid solution crystals GaSe1-xSx," Materials Chemistry and Physics,V. $154,152-157$ (2015).

[39] Molloy J.F., Naftaly M., Andreev Yu.M., Kokh K.A., Lanskii G.V., Svetlichnyi V.A., "Absorption anisotropy in sulfur doped gallium selenide crystals studied by THz-TDS," Optical Materials Express, Vol. 4, Issue 11, 24512459 (2014).

[40] Guo J., Xie J.J., Li D.J., Yang G.L., Chen F., Wang C.R., Zhang L.M., Andreev Yu.M., Kokh K.A., Lanskii G.V., Svetlichnyi V.A., "Doped GaSe crystals for laser frequency conversion" Light: Science \& Applications, V. 4, e362 (2015). DOI: 10.1038/lsa.2015.135.

[41] Qu Y., Kang Z.-H., Wang T.-J., Jiang Y., Andreev Y.M., Gao J.-Y., "The detection of carbon monoxide by the second harmonic generation of $\mathrm{CO}_{2}$ laser," Laser Phys. Lett. 4 (3), 238-241 (2007).

[42] Sitnikov A.G., Panchenko A.N., Tel'minov A.E., Genin D.E., SarkisovS.Yu., Bereznaya S.A., Korotchenko Z.V., Kazakov A.V., "Single-pulse $\mathrm{CO}_{2}$ laser with frequency doubler based on $\mathrm{GaSe}$ and $\mathrm{GaSe}_{0.7} \mathrm{~S}_{0.3}$ single crystals," Int. Symp. on High Current Electronics, 586-588 (2010).

[43] Molloy J., Naftaly M.. Andreev Yu.M., Kokh K.A., Lanskii G.V., Svetlichnyi V.A., "Dispersion equations for entire transparency range of GaSe," IRMMW-THz'2015, 23-28 August, Hong Kong, China, Report TS-3118041, 2015.

[44] RudV.Yu., RudYu.V., Vaipolin A.A., Bodnar I.V., Fernelius N., "Photosensitive structures on $\mathrm{CdGa}_{2} \mathrm{~S}_{4}$ single crystals," Semiconductors 37(11), 1321-1328 (2003).

[45] Kokh K.A., Andreev Yu.M., Svetlichnyi V.A., Lanskii G.V., Kokh A.E., "Growth of GaSe and GaS single crystals," Cryst. Res. Technol. 46 (4), 327-330 (2011).

[46] Feng Z.-S., Kang Z.-H.,Li X.-M.,GaoJ.-Y.,Andreev Yu. M.,Atuchin V.V.,Kokh K. A.,Lanskii G. V., Potekaev A.I., Shaiduko A.V., Svetlichnyi V.A., "Impact of fs and ns pulses on solid solution crystals $\mathrm{Ga}_{1-\mathrm{x}} \mathrm{In}_{\mathrm{x}} \mathrm{Se}$ and $\mathrm{GaSe}_{1-\mathrm{x}} \mathrm{S}_{\mathrm{x}}$," AIP Advances 4(3), 037104 (2014).

[47] Molloy J.F., Naftaly M., Andreev Yu.M.,Lanskii G.V., Lapin I.N., Potekaev A.I., Kokh K.A., Shabalina A.V., Shaiduko A.V., Svetlichnyi V.A., "Dispersion properties of GaS studied by THz-TDS," CrystEngComm. 16 (10), 1995-2000 (2014).

[48] Webb M.S., Eimerl D., Velsko S.P., "Wavelength insensitive phase-matched second-harmonic generation in partially deuterated KDP" J.Opt.Soc.Am.B Vol.9 (7), 1118-1127 (1992).

[49] Wei Shi, Yujie J. Ding, Fernelius N., Vodopyanov K., "Efficient, tunable, and coherent 0.18-5.27-THz source based on GaSe crystal: erratum" Optics letters Vol.28(2), 136 (2003).

[50] Nazarov M. M., Shkurinov A. P., Angeluts A. A., Sapozhnikov D. A., "On the choice of nonlinear optical and semiconductor converters of femtosecond laser into terahertz range," Radiophys. and Quantum Electron. 52(8), 536-545 (2009).

[51] Chen C.-W., Tang T.-T., Lin S.-H., Huang J.Y., Chang C.-S., Chung P.-K., Yen S.-T., Pan C.-L., "Optical properties and potential applications of $\varepsilon-\mathrm{GaSe}$ at terahertz frequencies," J. Opt. Soc. Am. B 26 (9), A58-A65 (2009).

[52] Vodopyanov K.L., Kulevskii L.A."New dispersion relationships for GaSe in the 0.65-18 km spectral region," Optics Communications, 118, 375-378 (1995). 